\title{
A clinical comparison of high dose and low dose of Suxamethonium
}

\section{Yadav R K, ${ }^{1}$ Majhi PC, ${ }^{2}$ Tiwari $\mathbf{D}^{3}$}

${ }^{1}$ Assistant professor, ${ }^{2}$ Professor and Head, ${ }^{3}$ Lecturer, Department of Anaesthesiology, CMS-TH, Bharatpur, Chitwan, Nepal

\section{ABSTRACT}

\section{Background}

Suxamethonium having its rapid onset and short duration of action makes this drug unique amongst the neuromuscular blocking drugs described so far. However, use of suxamethonium is associated with a large number of undesirable side effects.

\section{Objective}

To evaluate clinical effects of high and low dose of suxamethonium and to determine whether lower dose of suxamethonium can be used for any beneficial effects in terms of its various adverse effects e.g. cardiovascular responses, post-operative muscle pains and intraocular pressure.

\section{Methods}

A total of 100 patients were included in this prospective study. All these patients on preoperative clinical evaluation were assessed to have adequate airway. All the patients were divided in two groups, low dose group (group I) and High dose group (group II) with 50 patients in each at random. A standard anesthetic technique was adhered to all the patients and following parameters were observed on comparative basis: a. Fasciculation and post operative myalgia. b. Cardiovascular effects, c. Intraocular pressure.

\section{Observation}

The incidence of post Suxamethonium pain was significantly greater in group II. Increase in heart rate from baseline was significant in both groups. There was no significant difference between the two groups in the diastolic pressure but rise in systolic blood pressure was significant at all assessment times in both groups. This rise from control was statistically significant.

\section{Conclusion}

Suxamethonium can be used in lower doses $(0.5 \mathrm{mg} / \mathrm{kg})$ in elective cases without airway compromise. It gives benefits of reduced muscle pains, cardiovascular responses and intraocular hypertension.

\section{Key Words: Suxamethonium, high dose, low dose}


Journal of College of Medical Sciences-Nepal, 2013, Vol-9, No-2,

\section{INTRODUCTION}

Suxamethonium is a depolarizing type of neuromuscular blocking drug. Rapid onset and short duration of neuromuscular block produced by this drug makes it unique amongst the neuromuscular blocking drugs described so far. ${ }^{1}$ It produces adequate intubating conditions within 30-40 seconds which lasts for 6-7minutes in dosages used in anesthetic practice. ${ }^{2}$

However, use of suxamethonium is associated with a large number of undesirable side effects, the notable ones being myalgia and fasciculation, hyperkalemia, cardiac arrhythmias, specially bradycardia, raised intraocular, intragastric and intracranial pressure, mesenteric spasm, creatine phosphokinasuria, prolonged apnoea and myoglobinuria. Suxamethonium is also a well known trigger agent for malignant hyperthermia. Usual intravenous dose of suxamethonium is 1$1.5 \mathrm{mg} / \mathrm{kg}$ of body weight ${ }^{3}$ and many of the side effects have been seen to be dose related. This has also been hypothesized by waters and mapleson. ${ }^{4}$

A large dose of suxamethonium is well known to cause prolonged apnoea. ${ }^{5}$ In a work, published by Stewart et al where lower than normal doses were used, magnitude of cardiovascular responses e.g. heart rate and blood pressure (mean arterial blood pressure) was significantly less than those seen with conventional doses of suxamethonium. ${ }^{6}$

Various hypothesis put forward by waters and collier ${ }^{7}$ suggest altered balance of forces which develop at muscle fibrefascia interface or at sarcolemmal membrane, resulting in damage to motor units thereby causing hyperkalemia, myoglobinuria, creatine phosphokinasuria etc.
Dose of suxamethonium used plays an important role as it determines the amount of drug reaching neuromuscular junction finally.

Lower doses of suxamethonium will cause less prolonged apnea especially in cases of unknown plasma cholinesterase deficiency and in various disease states where enzyme levels are low. ${ }^{8}$

Thus, there is adequate evidence to believe suxamethonium in low doses would have fewer incidences of side effects especially myalgia, untoward cardiovascular responses, potassium and IOP changes without compromising its neuromuscular blocking properties.

\section{METHODS}

A total of 100 patients were studied after taking informed consent. All the patients were in the age group 15-45 years and belonged to ASA grade I or II. These patients presented electively for various types of surgery in CMS-Teaching Hospital, Bharatpur, Chitwan, Nepal. All these patients on preoperative clinical evaluation were assessed to have adequate airway and belonged to class I or II of Mallampati classification. ${ }^{9}$

Those patients having class III or IV airways were not included.

All the patients were divided in two groups 50 patients in each at random.

1. Low dose group (group I): Fifty patients belonging to this group were administered $\mathbf{0 . 5}$ $\mathbf{m g} / \mathbf{k g}$ of suxamethonium.

2. High dose group (group II): Remaining 50 patients were administered suxamethonium in a dose of $1.5 \mathrm{mg} / \mathrm{kg}$. 
Yadav RK et al. A clinical comparison of high

A standard anesthetic technique was adhered to in all these patients. All patients were premeditated with diazepam $0.02 \mathrm{mg} / \mathrm{kg}$ the before night and in the morning on the day of surgery. On the table an intravenous line using normal saline was started and baseline blood pressure recording were made. Induction of anesthesia was achieved with inj. Propofol upto a maximum of $2.5 \mathrm{mg} / \mathrm{kg}$ given over 20-30 seconds. After further 30 seconds, appropriate dose of suxamethonium $0.5 \mathrm{mg} / \mathrm{kg}$ or $1.5 \mathrm{mg} / \mathrm{kg}$ depending upon the group patient belong to, was given. Thereafter anesthesia was maintained using oxygen, Air, Isoflurane and long acting relaxants vecuronium.

Following observations were made:

1. Pulse and blood pressure were continuously monitored and recordings were obtained on the following occasions:
a. Before and after induction with Propofol
b. After administration of suxamethonium.
c. One minutes after intubation.
d. Five minutes after intubation.

2. Patients were followed up on the first and again on fourth or fifth day after operation and were asked about of occurrence of muscle pains. The responses to the questions were assessed and graded according to Table-1.

Table 1: grading of severity of muscle pain.

None Minor (Localized to one group of muscle) Moderate (Generalized aches)

Major (Interferes with normal activity and mobilization)
3. Intraocular pressure was measured at induction and at 2 min and 4 min after administration of suxamethonium. A SCHIOTZ tonometer was used for this purpose.

\section{Statistical analysis}

Data was analyzed by $\mathrm{Z}$ test. Comparison within the group for cardiovascular parameters and IOP was done using students paired ' $t$ ' test. For comparison between the two multiple linear regression analysis was undertaken controlling for baseline variables. The consolidated results of these analyses have been presented in appendix B. statistical significance was taken as $\mathrm{p}<0.05$.

\section{OBSERVATIONS}

Total of 100 patients were studied in both groups, fifty belonging to low dose group I and fifty in high dose group II. All patients were of ASA I or II status. Demographic data are statistically not significant. All the patients were followed up to enquire about the occurrence of muscle pains. The incidence of post Suxamethonium pain was significantly greater in group II $(\mathrm{p}<0.05)$. Twenty seven $(54 \%)$ patients in group II complained of muscle aches whereas only 17 (34\%) patients in group I had muscle aches of varying severity. None of the patients in low dose group had major post operative myalgia as against 5 in group II.

Table: 2 Incidence of post Suxamethonium of muscle pain (myalgia)

\begin{tabular}{l|c|c|}
$\begin{array}{l}\text { Grade of } \\
\text { myalgia }\end{array}$ & $\begin{array}{c}\text { Group 1 } \\
\text { (No. of pt.) }\end{array}$ & $\begin{array}{c}\text { Group 2 } \\
\text { (No. of pt.) }\end{array}$ \\
\hline None & 33 & 23 \\
Minor & 4 & 10 \\
Moderate & 13 & 12 \\
Major & 0 & 5
\end{tabular}


Journal of College of Medical Sciences-Nepal, 2013, Vol-9, No-2,

\section{Heart rate:}

Table 3 shows variations in heart rate from basal values. After adjusting for baseline values, the average heart rate after induction was higher by 7.5 beats/min in group II as compared to group I. Similarly heart rate elevation from baseline to one minute after intubation was also higher by 6.7 beats/ min in group II. These effects were significant $(p<0.05)$.however at five minutes after intubation, the difference from baseline was not significant $(p>0.05)$. within the groups increase in heart rate from baseline was significant in both groups at all assessment times (table 6).

\section{Systolic arterial pressure:}

There was considerable variation in both the groups and observations have been presented in table no.
4. Rise in systolic blood pressure was significant at all assessment times in both groups. However, in group II as compared with group I the systolic pressure rise to significantly higher values from control at induction (10.97 $\mathrm{mm}$ of $\mathrm{hg}$ ) and at one minute after intubation (13.83 $\mathrm{mm}$ of $\mathrm{hg}$ ). At five minutes after intubation, the significance was lost (table 7).

\section{Diastolic blood pressure:}

Diastolic pressure recordings were observed to be steady comparatively and large variations were unusual. This has been presented in table no.5. This observation is slightly different as there was no significant difference between the two groups in the diastolic pressure changes at induction as was the case in heart rate and systolic pressure (table

Table 3: Maximum variation of heart rate from basal values

\begin{tabular}{|c|ccccccccc} 
Group & \multicolumn{2}{|c|}{ Fall upto } & \multicolumn{2}{c|}{ No change } & \multicolumn{5}{c|}{ Rise upto } \\
& $20 \%$ & $10 \%$ & & $10 \%$ & $20 \%$ & $30 \%$ & $40 \%$ & $50 \%$ & $>50 \%$ \\
I & 1 & 1 & 4 & 28 & 15 & 1 & Nil & Nil & Nil \\
II & 1 & 2 & Nil & 1 & 6 & 13 & 16 & 8 & 3 \\
\hline
\end{tabular}

Table 4: maximum variation of systolic blood pressure from control values.

\begin{tabular}{|cccccccccc} 
Group & \multicolumn{2}{|c}{ Fall upto } & No change & \multicolumn{7}{c}{ Rise upto } \\
& $20 \%$ & $10 \%$ & & $10 \%$ & $20 \%$ & $30 \%$ & $40 \%$ & $50 \%$ & $>50 \%$ \\
I & Nil & 1 & Nil & 18 & 22 & 8 & 1 & Nil & Nil \\
II & Nil & 2 & Nil & 1 & 19 & 17 & 9 & 2 & Nil
\end{tabular}

Table 5: maximum variation of diastolic blood pressure from basal values

\begin{tabular}{cccccccccc} 
Group & \multicolumn{2}{c}{ Fall upto } & No change & \multicolumn{8}{c}{ Rise upto } \\
& $20 \%$ & $10 \%$ & & $10 \%$ & $20 \%$ & $30 \%$ & $40 \%$ & $50 \%$ & $>50 \%$ \\
I & 1 & 2 & 2 & 24 & 16 & 3 & 2 & Nil & Nil \\
II & 1 & 2 & 1 & 3 & 14 & 14 & 12 & 3 & Nil
\end{tabular}


Yadav RK et al. A clinical comparison of high.

Cardiovascular responses: values in mean (SD)

Table 6: Heart rate (beats/min)

\begin{tabular}{|c|c|c|c|c|}
\hline Group & Control & After Induction & $1 \mathrm{~min}$ after induction & 5 min after induction \\
\hline I (low) & $85(14.07)$ & $90(13.56)$ & 104(16.39) & $91(10.36)$ \\
\hline I I (high) & $84(14.46)$ & $97(16.05)$ & $110(19.95)$ & $92(12.44)$ \\
\hline
\end{tabular}

Table 7: systolic arterial pressure (mm of hg)

\begin{tabular}{|c|c|c|c|c|}
\hline Group & Control & After Induction & $1 \mathrm{~min}$ after induction & 5 min after induction \\
\hline I (low) & $125(12.32)$ & $129(12.22)$ & $140(11.06)$ & $131(11.43)$ \\
\hline I I (high) & $124(9.55)$ & $140(9.44)$ & $154(14.92)$ & $132(11.26)$ \\
\hline
\end{tabular}

Table 8: diastolic arterial pressure ( $\mathbf{m m}$ of $\mathbf{h g}$ )

\begin{tabular}{|c|c|c|c|c|}
\hline Group & Control & After Induction & $1 \mathrm{~min}$ after induction & $5 \mathrm{~min}$ after induction \\
\hline I (low) & $78(6.16)$ & $82(5.24)$ & $86(4.87)$ & $81(4.98)$ \\
\hline I I (high) & $74(5.82)$ & $82(6.23)$ & $92(5.43)$ & $84(4.71)$ \\
\hline
\end{tabular}

\section{Intra ocular pressures}

were recorded at three occasions, after induction, 2 minutes and 4 minutes after drug (table 15). Tension was measured in right eye because of convenience. Mean pre-relaxant IOP in low group was $13.76(3.35) \mathrm{mm}$ of hg which rise to 20.22(4.35) $\mathrm{mm}$ of hg after intubation. This rise from control was statistically significant. However, at 4 min after suxamethonium values were restored towards normal that is $14.04(2.85) \mathrm{mm}$ of hg and statistical significance disappeared

Table 9: Intraocular pressure recordings: values expressed as mean (SD) $\mathbf{m m}$ of hg

\begin{tabular}{|cccc} 
Group & After Propofol & $\mathbf{2}$ minute after suxamethonium & $\mathbf{4}$ minute after suxamethonium \\
I & $13.76(3.35)$ & $20.22(4.35)$ & $14.05(2.92)$ \\
\hline II & $14.15(4.03)$ & $21.11(3.92)$ & $16.63(3.36)$ \\
\hline
\end{tabular}

\section{DISCUSSION}

Post operative myalgia though considered to be minor side effect. Of the many regimes which have been proposed as a mean to reduce this pain, most effective and widely used method is pretreatment with a small dose of non-depolarizing relaxants. ${ }^{\mathbf{1 0}}$
The present study has demonstrated a reduced incidence of pain in patients given a smaller dose of suxamethonium. These results are comparable those obtained by Stewart et al. ${ }^{6}$ Fasciculation observed in low dose group of patients were of finer quality and less discernible than in high dose group. 
Journal of College of Medical Sciences-Nepal, 2013, Vol-9, No-2,

However, there seems to be little correlation between visible fasciculation and incidence of muscle pain. This was shown by Urbach in $1960 .{ }^{20}$ muscles pains however, seem to be related to occurrence of hyperkalemia ${ }^{7}$ and creatine phosphokinesuria. ${ }^{12}$

Suxamethonium is known to produce arterial pressure changes as a result of ganglionic stimulation. The main adverse effect of Suxamethonium on cardiovascular system has been bradycardia and nodal rhythm ${ }^{13}$, but they are much more common in children and after second successive dose. Leiman confirmed elevation in blood pressure and heart rate following suxamethonium in hypoxic and hypoxic: hypercarbic doges. ${ }^{14}$

In present study where cardiovascular parameters were significantly raised at all reference times. It is worthwhile to mention that in study by Stewart et al magnitude of increase in cardiovascular variables was higher than those observed in present study. ${ }^{6}$ Suxamethonium has been well known for causing rise in intraocular tension. Apart from Suxamethonium, there are many factors which affect IOP. Arterial pressure and its correlation with IOP have been studied extensively. This is in agreement with Macri and Schreuder and Linnssen who reported poor or no correlation between systemic pressures and IOP. ${ }^{15}$ The present study demonstrated a significant rise in mean IOP following suxamethonium and intubation in both the groups. This had also been noticed by Craythrone and Taylor et al . 16,17 These findings were further confirmed by Pandey et al, who demonstrated that tracheal intubation also accentuated rise in IOP. ${ }^{17}$
In an attempt to analysis dose dependent types of responses, Katz and Eakins demonstrated marked increase in resting tension of medical rectus in cat's eye following administration of suxamethonium in dosage of $30-150 \mathrm{ug} / \mathrm{kg} .{ }^{18} \mathrm{Joshi}$ and Bruce using $0.5 \mathrm{mg} / \mathrm{kg}$ and $1.0 \mathrm{mg} / \mathrm{kg}$ of suxamethonium found higher dose caused less intraocular hypertension than the smaller. Cook on the other hand found that $1 \mathrm{mg} / \mathrm{kg}$ of Suxamethonium caused a significant increase in IOP and that a higher dose of $2.5 \mathrm{mg} / \mathrm{kg}$ had a similar effect suggesting dose above normal paralyzing dose was neither critical nor protective. ${ }^{19}$ The present study does not demonstrate any such difference. However, in high dose group mean IOP value at 4 min after suxamethonium [16.63(3.36)] was higher than pre relaxant value [14.15(4.03)]. In low dose group values returned to almost normal [table 15].It is possible that stress response to laryngoscopy and intubation has contributed to rise in IOP as was demonstrated by Pandey et al. this was also shown by Wynands et al and Bowen. ${ }^{20}$

Considering the present evidence available low dose of suxamethonium does not appear to cause less compromise intraocular pressure than higher doses especially in cases requiring intubation. This is further substantiated by present study. Our study, however, also showed mean IOP rise at 4 min interval in group II to be significantly higher as compared to group I. this points towards possibility of longer duration of intraocular hypertension caused by higher dose of suxamethonium.

\section{CONCLUSION}

Low dose of suxamethonium has been assessed in this study to reduce incidence of adverse effects. Present study, supported by Low doses are also 
Yadav RK et al. A clinical comparison of high

associated with reduction in incidence of muscle pains, cardiovascular responses and shorter duration of intraocular hypertension. To conclude, Suxamethonium can be used in lower doses $(0.5$ $\mathrm{mg} / \mathrm{kg}$ ) in elective cases without airway compromise. It gives benefits of reduced muscle pains, cardiovascular responses and intraocular hypertension.

\section{REFERENCES}

1. Castillo JA, Debeer EJ. Neuromuscular blocking action of suxamethonium. $J$ of PharmacolExpTher 1950: 97:458.

2. Schwarz S,Ilias W, Lackner F, et al. rapid tracheal intubation with vecuronium. The priming principle. Anesthesiology 1985;62:388-93.

3. Froancois Donati and David R. Brevan. Neuromuscular Blocking Agent. In: Barash PG, Cullen BF, Stoelting RK. Clinical Anesthesia, $5^{\text {th }}$ ed. Philadelphia: Lippincott Williams and Wilkins; 2006.p.427.

4. Waters DJ, Mapleson WW. Suxamethonium pains and observation. Anesthesia 1971;26:127-41.

5. Bush GH. Prolonged apnoea due to suxamethonium. Brit J Anaes1961;33:454.

6. Stewart KG, Hopkins,PM, Dean SG. Comparision of high and low doses of suxamethonium. Anesthesia 1991;46:833-6.

7. Collier CB. Suxamethonium pains and early electrolyte changes. Anesthesia 1978; 33:454.

8. Viby-Mogensen J.Correlation of suxamethonium duration of action with plasma cholinesterase activity in subjects with genotypically normal enzyme. Anesthesilogy 1980;53:513-20.

9. Mallampatti SR, Galt SP, Gugino LD, et al. A clinical sigh to predict difficult intubation: a prospective study. Can Anesth Society Journal 1985;32:429-34.

10. Laurence AS. Myalgia and biochemical changes following intermittent suxamethonium administration. Effects of alcuronium, lignocaine, midazolam and suxamithoniumpretreatment on serum myoglobin, creatinine kinase and myalgia. Anesthesia 1987;42:503-10.

11. Lamoreaux LF, Urbach KF. Incidence and prevention of muscle pain following administration of succinylcholine. Anesthesiology 1960;21:394.

12. Stoelting RK, Peterson C. adverse effects ofincreaesd succinylcholine dose following dtubocurarine pretreatment. AnestAnalg1975; 54: $282-8$.

13. Leigh MD, McCoy DD, Belton KM, et al. bradycardia followings intravenous administration of succinylcholine to infannts and children. Anesthesiolgy 1957;18:698.

14. Leiman BC, Katz J, Butler BD. Mechanism of suxamethonium induced cardiac arrythmia in hypoxic or hypoxic: hypercarbic dogs. AnaesthAnalg 1987;66:1292-7.

15. Schreuder M, Linnssen GH. Intraocular pressure and anesthesia. Anesthesia 1972;27:165-90. 
Journal of College of Medical Sciences-Nepal, 2013, Vol-9, No-2,

16. Craythorne NWB, Rottnetien MS, Drippe RD. the effect of succinylcholine on intraocular pressure in adults, infants and children during general anesthesia. Anesthesiology 1957;21:39-40.

17. Taylor TH, Mulchay M. suxamethonium chloride in intraocular surgery. Brit $J$ Anes 1968;40:113-8.

18. Tammisto T, Airaksinem M. increase of creatine kinase activity in serum as a sigh of muscular injury caused by intermittently administredsuxamethonium during halothane anesthesia. Brit J Anaes 1966;5105.

19. Cook JH. The effect of suxamethonium on intraocular pressure. Anesthesia 1981;36:359-65.

Bowen DJ, McGrand JC, Hamilton AG. Intraocular pressure after suxamethonium and endotracheal intbation. Anesthesia 1978;33:518-22.
16. Craythorne NWB, Rottnetien MS, Drippe RD. the effect of succinylcholine on intraocular pressure in adults, infants and children during general anesthesia. Anesthesiology 1957;21:39-40.

17. Taylor TH, Mulchay M. suxamethonium chloride in intraocular surgery. Brit $J$ Anes 1968;40:113-8.

18. Tammisto T, Airaksinem M. increase of creatine kinase activity in serum as a sigh of muscular injury caused by intermittently administredsuxamethonium during halothane anesthesia. Brit J Anaes1966;5105.

19. Cook JH. The effect of suxamethonium on intraocular pressure. Anesthesia 1981;36:359-65.

20. Bowen DJ, McGrand JC, Hamilton AG. Intraocular pressure after suxamethonium and endotracheal intbation. Anesthesia 1978;33:518-22. 